\title{
As filhas da Caducidade: a moda e a morte ${ }^{1}$
}

Lucia Aparecida Felisberto Santiago

UFMG

Resumo: Este texto tem como objeto de estudo as cenas finais do filme $O$ bebê santo de Mâcon, do diretor inglês Peter Greenaway. Nosso olhar se fixa nos acontecimentos ligados ao corpo, às vestes do pequeno santo, à morte e ao significado alegórico das coisas. Buscaremos compreender de que forma todos esses elementos estão ligados à moda. Numa tentativa de colar tantos "fragmentos", nosso fio condutor será a teoria benjaminiana da alegoria, conforme está discutida no livro Origem do drama barroco alemão, especificamente no capítulo "Alegoria e drama barroco".

Palavras-Chave: alegoria, drama barroco, moda e morte.

Canto:

A criança retorna ao seu criador após suas atribuições na Terra. Fomos abençoados pela sua presença.

Povo:

Esta criança nos foi levada muito cedo.

Se tivesse vivido teria nos abençoado.

$\mathrm{E}$ aos meus filhos.

$\mathrm{E}$ aos filhos dos meus filhos.

Bênçãos futuras nos foram negadas.

Graças à avareza da Igreja.

A criança nasceu para nós.

Não nos abandonaria.

Sua beleza nos foi negada.

Sua presença nos foi negada.

Povo:

Ele não se oporá a tocarmos sua roupa Um botão do seu casaco, um fio...

As contas da pobreza, as contas da pobreza.

A coroa da força, a coroa da força.

As sandálias da perseverança, perseverança. 
O Manto da piedade,

o manto da piedade.

O manto da prudência comprado dos turcos,

Bagdá, Assurbanipal,

Cadosa, Barbarossa.

O manto da prudência.

O manto da castidade,

da castidade.

O debrum da humildade,

o debrum.

Canto:

Esta criança deixa o mundo em treze estágios.

Povo:

Criança, abençoa-me com o seu cabelo.

Canto:

Tantos estágios como os que levou para vir.

Povo:

Criança, abençoa-me com os dedinhos de tuas mãos.

Abençoa-me com os pés que caminharam a Terra.

Criança, abençoa-me com as pernas que andaram com Deus.

Criança, abençoa-me com as mãos que rezaram para Deus.

Abençoa-me com os braços que poderiam ter-me abraçado.

Abençoa-me com os dedos dos pés.

Criança, abençoa-me com a sua virilidade.

Criança, abençoa-me com o seu corpo.

Canto:

Que Deus nos abençoe a todos.

(Diálogo final do filme $O$ bebê santo de Mâcon, de Peter Greenaway).

Qualquer um dos filmes do diretor Peter Greenaway, um dos grandes nomes da cinematografia contemporânea, pode nos levar às mais diversas possibilidades de estudo. Greenaway, com um olhar multifacetado transita pela linguagem verbal e nãoverbal. Wilton Garcia em um estudo sobre a intertextualidade da obra criada pelo diretor inglês diz que:

Os filmes de Greenaway provocam, certamente, uma atitude polêmica devido às suas cenas bizarras, com citações complexas em destaque. Com isso, fica a impressão de que este diretor, controlando o exercício da distribuição da forma e do conteúdo, 
parece apontar, como simulação, um projeto estético de inovações múltiplas, mesmo que sejam apenas passagens concebidas dentro da linguagem contemporânea. Peter Greenaway, como meganarrador, acaba compondo, com originalidade, uma estética combinada com grande acuidade, proporcionando um corpus detalhado de emaranhados de significações. Na verdade, Greenaway, como autor, deve ser considerado como fruto da linguagem - o enquadramento de um fenômeno social da criação (suporte significante do sujeito). Além disso, este cineasta trata verticalmente de diferentes áreas das práxis humanas: cinema, vídeo, teatro, literatura, psicanálise, filosofia, antropologia, história, gastronomia, culinária, violência, sexualidade e religião, entre outros. Nesse conjunto associativo, formado pela própria concepção fílmica dentro da linguagem do cinema contemporâneo, nasce a obra "greenawayana". 2

Tudo isso é resultado da sua formação de documentarista, montador e artista plástico, do cinema experimental e de influências como a do cineasta Alain Resnais. Não importa qual o roteiro, o tema, o ator ou o lugar, tudo será transformado em algo grandioso. Às vezes temos a impressão de estar diante de uma pintura, uma escultura, um cenário de teatro, um texto barroco ou, até mesmo, diante da "obra de arte total" (Gesamtkunstwerk), como nas "festas barrocas" onde todas as formas de expressão artística estão juntas ao mesmo tempo. O diretor britânico possui uma maneira peculiar de trabalhar com os contrastes entre luz e sombra, o olhar e o não-olhar, o bem e o mal, o belo e o feio, o grotesco e o sublime, a vida e a morte, o excesso, a ambiguidade, a repetição, a metáfora e a alegoria. Parece ser quase impossível fazer uma "leitura singular das coisas", ${ }^{3}$ das pessoas ou de qualquer outro elemento em seus filmes. Peter Greenaway parece construir seu trabalho como um artista constrói um mosaico. Pequenas partes juntas formam um todo repleto de significados e leituras. Bem ao modo benjaminiano.

Aqui falaremos do filme $O$ bebê santo de Mâcon, no qual Greenaway nos conta a história de uma virgem que aparentemente deu à luz um menino. Um drama repleto do moralismo do século XVII e uma abordagem do "fanatismo religioso da crença e da fé". ${ }^{4}$ Um espetáculo dentro de um espetáculo. Uma sobreposição de "imagens visuais, sonoras, verbais" 5 e não-verbais com múltiplos significados. Entre idas e vindas sobre o nascimento do bebê e sobre seus verdadeiros pais, um espetáculo se confunde com o outro, ao mesmo tempo em que o bebê é transformado em santo, num ser divino. O 
povo quer tocá-lo, na tentativa de graças alcançar. No meio de tantos conflitos, o pequeno ser santificado morre.

O olhar do espectador nas cenas finais do filme pode ser de absoluta incredulidade. Especialmente em relação aos acontecimentos ligados ao corpo e às vestes do pequeno santo, à morte e ao significado alegórico das coisas diante dos seus olhos. Buscaremos compreender de que forma todos esses elementos estão ligados à moda. Numa tentativa de colar tantos "fragmentos", nosso fio condutor será a teoria benjaminiana da alegoria conforme está discutida no livro Origem do drama barroco alemão, especificamente no capítulo "Alegoria e drama barroco".

\section{A alegoria da morte segundo Walter Benjamin}

Para Benjamin a "estrutura alegórica" do drama barroco é a possibilidade de leitura e assimilação dos "conteúdos" materiais da própria época, uma tentativa de "recompor suas ruínas e ressuscitar seus mortos". Isto não quer dizer "salvação". Pelo menos não no sentido clássico. Segundo Sérgio Paulo Rouanet na apresentação da tradução brasileira do livro Origem do drama barroco alemão:

Salvar o Barroco, para Benjamin, não significa trazer à superfície o esquema estrutural do seu drama, mas de algum modo, através dessa tentativa, recompor suas ruínas e ressuscitar seus mortos. Benjamin quer redimir esse Barroco, porque sente que, mais que qualquer outro, nosso presente é visado por ele (...) Benjamin quer redimir as coisas através das idéias: alegorias dos fenômenos (...) Salvar o Barroco e salvar-nos nele significa preservar sua capacidade de ver na história "tudo o que é prematuro, sofrido e malogrado", pois só a esse preço podemos manter viva a consciência do sofrimento $(\ldots)^{6}$

É importante compreendermos "o drama barroco como forma-limite (a partir) de uma esfera mais alta, a da teologia, (...) no sentido da história, de uma teologia da história, e não estaticamente, no sentido de uma economia da salvação, previamente assegurada (...)". ${ }^{7}$

Dos elementos presentes na história como "história mundial do sofrimento", a morte é o que nos interessa, pois a "morte é o conteúdo mais geral da alegoria barroca" 8 e é também o seu "meio". Desta forma a morte é um elemento comum presente no 
"cerne da alegoria" e no "cerne da história". Assim a morte pode transitar "entre os dois planos" de forma comum, justificando "o papel central da alegoria como linguagem capaz de exprimir, no drama barroco, a concepção da história-destino". 9

Benjamin diz que "do ponto de vista da morte, a vida é o processo de produção do cadáver". ${ }^{10}$ A alegoria "significa a morte, e se organiza através da morte", ${ }^{11}$ e no drama barroco do século XVII "o cadáver é o supremo adereço cênico". ${ }^{12}$ Passamos todo o tempo lidando com o "vivo" e o "morto":

Se com a morte, portanto, o espírito se libera, o corpo atinge, nesse momento, a plenitude dos direitos. É evidente: a alegorização da physis só pode consumar-se em todo o seu vigor no cadáver. Se os personagens do drama barroco morrem, é porque somente assim, como cadáveres, têm acesso à pátria alegórica (...) para que acendam à condição de cadáver. ${ }^{13}$

De acordo com as regras da emblemática, "o organismo deveria ser despedaçado, para que em seus fragmentos a significação autêntica, fixa e escritural, se tornasse legível (...)" ${ }^{14}$ Isto quer dizer que somente o corpo em partes pode ser significado. É como “cadáver" que o corpo despedaçado entra na "na pátria alegórica".

\section{A crueldade do drama barroco: $O$ bebê santo de Mâcon}

O corpo humano inteiro não pode entrar num ícone simbólico. Mas uma parte do corpo é apropriada para a constituição desse ícone. $^{15}$

Aqui não falaremos sobre o tema do martírio barroco, pois, o bebê não sofre dor física. Segundo Benjamim, "o martírio prepara (...) o corpo dos vivos para a sua metamorfose emblemática". ${ }^{16}$

Nosso objeto é o corpo inteiro, sem dor, sem sofrimento. O corpo que será despedaçado. E é justamente o despedaçar do corpo que nos chama a atenção nas cenas finais do filme de Greenaway, onde a crueldade do Barroco se faz presente. Após a sua morte o bebê é preparado para um cortejo. $\mathrm{O}$ cadáver do bebê santificado segue entre o povo.

O povo cego de desesperança diz: "ele não se oporá a tocarmos sua roupa". ${ }^{17} \mathrm{E}$ o povo toca as vestes do pequeno santo. De repente, esse mesmo povo não quer mais 
apenas tocar as roupas daquele que representa a "salvação". Necessita de algo mais concreto. Começa então uma espécie de partilha das vestes do bebê:

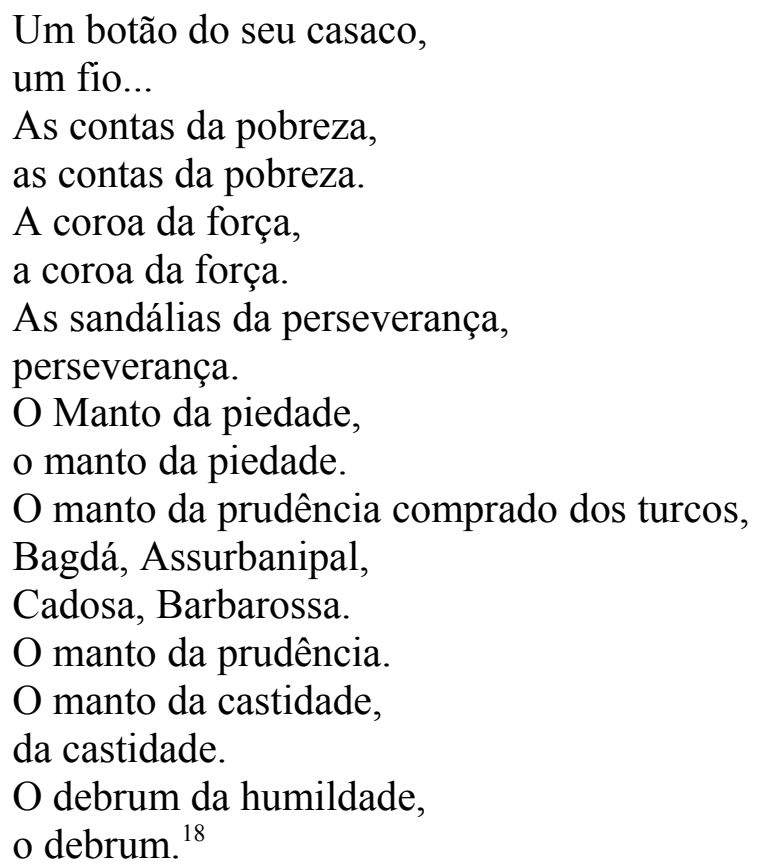

E a criança fica desnuda. O povo levou suas vestes. Cada homem e mulher têm agora um "fragmento" das roupas do bebê. O pequenino corpo nu sobre a mesa há muito tempo não reclama. Ele está mudo. Segundo Benjamin, "a criatura muda pode ter esperança de salvar-se através das coisas significadas". ${ }^{19}$

Os "fragmentos" das vestes e os objetos que compõem o traje do bebê santificado são metáforas das “coisas vindouras". Mas a posse das vestes, dos objetos e dos seus significados não são o suficiente para o povo. Com a chegada da morte desaparece a promessa de dias melhores abençoados pelo bebê. Após a partilha das vestes, o povo toma para si o corpo do menino santo. Mas não o "corpo humano inteiro", porque nesta condição ele, o corpo, ainda não é um ícone, e sim os "fragmentos" deste pequeno corpo santificado pelo fanatismo, pelo oportunismo da cegueira, pela necessidade e esperança de um futuro melhor que o presente e o passado:

\footnotetext{
Criança, abençoa-me com os dedinhos de tuas mãos. Abençoa-me com os pés que caminharam a Terra. Criança, abençoa-me com as pernas que andaram com Deus. Criança,
} 
abençoa-me com as mãos que rezaram para Deus.

Abençoa-me com os braços que poderiam ter-me abraçado.

Abençoa-me com os dedos dos pés.

Criança,

abençoa-me com a sua virilidade.

Criança,

abençoa-me com o seu corpo. ${ }^{20}$

Assim, "o cadáver vai se desprendendo do corpo, pedaço por pedaço". ${ }^{21}$ Como num passe de mágica a mesa onde estava o cadáver do bebê fica vazia. Não há mais um corpo. Agora existem por todos os lugares "fragmentos" daquele que um dia foi um corpo, um cadáver, um bebê. Agora, de fato, o bebê tornou-se santo. Com os "fragmentos" do pequenino corpo a "significação autêntica, fixa e escritural" tornou-se "legível". Os "fragmentos" do seu corpo santo, espalhados entre o povo, legitimam a sua entrada na "pátria alegórica" tornando-se um "ícone simbólico". O bebê santo de Mâcon tornou-se uma alegoria. O corpo foi então salvo.

\section{A moda e a morte}

MODA: Sou a Moda, tua irmã.

MORTE: Minha irmã?

MODA: Sim. Não te lembras que nós duas nascemos da Caducidade?

MORTE: Que tenho eu de me lembrar, se sou inimiga da memória?

MODA: Mas eu me lembro muito bem e sei que ambas vivemos continuamente a desfazer e mudar as coisas aqui embaixo, apesar de ires, para isso, por um caminho e eu, por outro (...) ${ }^{22}$

Para o poeta italiano Giacomo Leopardi a moda e a morte nasceram da caducidade. Cada uma à sua maneira busca a novidade. Ambas usam de artimanhas para encontrar o "novo", vivem continuamente mudando e desfazendo as coisas para alcançarem seus objetivos. A linha que separa a moda e a morte é traçada alegoricamente, ou seja, o seu real significado encontra-se sempre encoberto por algo que nunca tem sentido literal.

Pensar na moda como irmã da morte pode parecer algo, a princípio, um pouco distante, mas, na verdade, há nisso um parentesco no mínimo interessante. Com a necessidade principalmente feminina do novo, rapidamente o que está na moda deixa de 
ser novidade, quer dizer torna-se algo "morto", abrindo espaço para o novo, o que quer dizer, o "vivo".

A moda está sempre em busca do futuro, e o "faro" feminino contribui para a procura constante das “coisas vindouras". Esta movimentação na moda em busca da novidade se deve em parte a alguns motivos individuais como o desejo de mudança, a busca pela aparência perfeita, o gosto em se vestir bem, a necessidade de se encaixar nos padrões estabelecidos e também por motivos relacionados a questões sociais de pertencimento de um grupo, poder, ocupação profissional, entre tantos outros motivos.

Em um dos fragmentos do arquivo temático "Moda", do livro das Passagens, Benjamim atribui à moda a possibilidade de antecipar uma época, fazendo uma aproximação entre a moda e a arte:

Para o filósofo, o aspecto mais interessante da moda é sua extraordinária capacidade de antecipação. É consenso que a arte, muitas vezes, geralmente por meio de imagens, antecipa em anos a realidade perceptível. Ruas ou salas puderam ser vistas em suas variadas cores brilhantes bem antes que a técnica, através de anúncios luminosos ou outros dispositivos, as colocasse sob uma luz desse tipo. Da mesma forma, a sensibilidade individual de um artista em relação ao futuro ultrapassa em muito aquela da dama da sociedade. E, entretanto, a moda está em contato muito mais constante, muito mais preciso, com as coisas vindouras graças ao faro incomparável que o coletivo feminino possui para o que nos reserva o futuro. Cada estação da moda traz em suas novas criações alguns sinais secretos das coisas vindouras, e quem os soubesse ler, saberia antecipadamente não só quais seriam as novas tendências da arte, mas também a respeito das novas legislações, guerras e revoluções. Aqui, sem dúvida reside o maior encanto da moda, mas também a dificuldade de torná-lo frutífero. ${ }^{23}$

O desejo pela "novidade" traz consigo a "antecipação" do futuro. É o desejo transformado em mercadoria que aproxima a moda da morte. Pois o desejo de renovar, de nascimento - que é a "condição natural", faz com que a moda "supere" a morte - que é uma "condição social".

Sobre isto Benjamin escreve:

(...) a moda inaugurou o entreposto dialético entre a mulher e a mercadoria - entre o desejo e o cadáver. Seu espigado e atrevido caixeiro, a morte, mede o século em braças e, por economia, ele 
mesmo faz o papel de manequim e gerencia pessoalmente a liquidação que, em francês, se chama révolution. Pois a moda nunca foi outra coisa senão a paródia do cadáver colorido, provocação da morte pela mulher, amargo diálogo sussurrado com a putrefação entre gargalhadas estridentes e falsas. Isso é a moda. Por isso ela muda tão rapidamente; faz cócegas na morte e já é outra, uma nova, quando a morte a procura com os olhos para bater nela $(\ldots) .^{24}$

Comercialmente, a moda sobrevive daquilo que está nas vitrines. O design de moda durante o processo de pesquisa, criação e produção de uma coleção pode perceber, quer dizer "antecipar", elementos ou "fragmentos" que serão as novidades da próxima coleção. E a coleção, do presente, que ganha vida em um desfile ou em um ensaio fotográfico mostra em um jogo de esconde-esconde as "coisas vindouras". Vale a pena lembrar que esta antecipação do futuro pode aparecer dentro de um ano ou dois e até mesmo três anos. Podemos dizer que uma coleção já nasce morta. Porque o "vivo" que vai para as vitrines já chega ali com cheiro de "morto". Já caducou.

De fato a moda, da forma como Benjamin se refere ao "cadáver colorido", provoca mesmo a morte, pois a busca pela novidade parece materializar o desejo tão rapidamente que, quando a "morte" chega à procura da novidade, a própria novidade já se tornou outro desejo materializado, ou seja, algo "vivo". Assim constatamos que "a moda consiste de extremos. Como ela, por natureza, procura os extremos, nada mais lhe resta ao abandonar uma determinada forma senão remeter-se ao seu contrário". 25

Ainda pensando de acordo com Benjamin, "a alegoria se instala mais duramente onde o efêmero e o eterno coexistem mais intimamente". ${ }^{26} \mathrm{O}$ corpo humano é um “cadáver colorido" circulando pela cidade em busca de algo "vivo". A moda e a morte estão desta forma, repletas de caducidade, pois cada uma, à sua maneira, busca a "novidade" e abre caminho para as "coisas vindouras".

\section{O corpo, a morte, a alegoria e a moda}

Como o corpo, a morte e a alegoria se fazem presentes na moda? A resposta para esta pergunta talvez seja tão complexa e densa quanto o próprio livro tomado como fio condutor para a construção deste texto. 
A moda e a morte podem ser, de fato, irmãs, já que as duas estão sempre deixando no passado algo que caducou. Anunciam o futuro, ao mesmo tempo em que trazem a "novidade". Esta "novidade" é transformada pela moda em mercadoria. O desejo pelo novo, quando adquire a categoria de mercadoria, faz com que a moda "supere" a morte. É a morte quem conduz o corpo à condição de "cadáver". Mas a moda, à sua maneira, também pode conduzi-lo à condição de "cadáver colorido".

Assim como no filme de Greenaway as novidades da moda nos são reveladas de forma fragmentada. O corpo humano, no filme $O$ bebê santo de Mâcon, passa da condição de "inteiro" para a condição do "fragmento". Na moda, o corpo humano parece ser todo o tempo composto de "fragmentos". Seguindo o pensamento de Benjamim, se o corpo humano precisa ser despedaçado para entrar na "pátria alegórica", o corpo humano na moda perde sua corporeidade física para adquirir uma conotação alegórica.

Abstract: This text has as subject of study the final scenes of the film directed by the English director Peter Greenaway The baby of Mâcon. Our gaze is fixed on events connected to the body, the clothes of the small saint, the death and the allegorical meaning of things. Our intention is to understand how all these elements are linked to fashion. Attempting to paste so many "fragments", our guiding principle is the Walter Benjamin's theory of allegory, as this is exposed in his book The origin of german tragic drama, specifically in the chapter "Allegory and tragic drama".

Keywords: allegory, fashion, tragic drama.

\section{Referências Bibliográficas}

BENJAMIN, Walter. Origem do drama barroco alemão. Trad. Sérgio Paulo Rouanet. São Paulo: Brasiliense, 1984.

BENJAMIN, Walter. Passagens. Belo Horizonte: Editora UFMG; São Paulo: Imprensa Oficial do Estado de São Paulo, 2006. 
GARCIA, Wilton. Introdução ao cinema intertextual de Peter Greenaway. São Paulo: Annablume; UniABC, 2000.

LEOPARDI, Giacomo. Diálogo da moda e a morte. In: LUCCHESI, Marco (Org.). Opúsculos morais: poesia e prosa. Trad. Affonso Félix de Sousa et al. Rio de Janeiro: Nova Aguilar, 1996, p. 324-327.

ROUANET, Sérgio Paulo. Apresentação. In: BENJAMIN, Walter. Origem do drama barroco alemão. Trad. Sérgio Paulo Rouanet. São Paulo: Brasiliense, 1984, p.11-47.

\section{Referência Filmográfica}

O BEBÊ santo de Mâcon. Peter Greenaway, 1993, 117 min., son., color., ingl., legendado.

\section{Notas}


${ }^{1}$ Este artigo é uma versão revista do trabalho final apresentado à disciplina: Seminário de Teoria da Literatura e outras disciplinas: os sentidos em Walter Benjamin, ministrada pelos professores doutores Elcio Loureiro Cornelsen e Georg Otte, no Programa de Pós-Graduação em Letras - Estudos Literários, da Faculdade de Letras da UFMG, no segundo semestre de 2006.

${ }^{2}$ GARCIA. Introdução ao cinema intertextual de Peter Greenaway, p. 21 e 22.

${ }^{3}$ GARCIA. Introdução ao cinema intertextual de Peter Greenaway, p. 21.

${ }^{4}$ GARCIA. Introdução ao cinema intertextual de Peter Greenaway, p. 21.

${ }^{5}$ GARCIA. Introdução ao cinema intertextual de Peter Greenaway, p. 24.

${ }^{6}$ ROUANET. Apresentação, p. 46- 47.

${ }^{7}$ BENJAMIN. Origem do drama barroco alemão, p. 240.

${ }^{8}$ ROUANET. Apresentação, p. 38.

${ }^{9}$ ROUANET. Apresentação, p. 40.

${ }^{10}$ BENJAMIN. Origem do drama barroco alemão, p. 241.

${ }^{11}$ ROUANET. Apresentação, p. 38.

${ }^{12}$ BENJAMIN. Origem do drama barroco alemão, p. 242.

${ }^{13}$ BENJAMIN. Origem do drama barroco alemão, p. 241.

${ }^{14}$ BENJAMIN. Origem do drama barroco alemão, p. 240.

${ }^{15}$ Integrum humanum corpus symbolicam iconem ingredi non posse, partem tamen corporis ei constituendae non esse ineptam. Texto sobre as normas da emblemática, citado por Benjamin; BENJAMIN. Origem do drama barroco alemão, p. 240.

${ }^{16}$ BENJAMIN. Origem do drama barroco alemão, p. 241.

${ }^{17}$ Diálogo final do filme $O$ bebê santo de Mâcon (1993), de Peter Greenaway.

${ }^{18}$ Diálogo final do filme $O$ bebê santo de Mâcon (1993), de Peter Greenaway.

${ }^{19}$ BENJAMIN. Origem do drama barroco alemão, p. 250.

${ }^{20}$ Diálogo final do filme $O$ bebê santo de Mâcon (1993), de Peter Greenaway.

${ }^{21}$ BENJAMIN. Origem do drama barroco alemão, p. 241.

${ }^{22}$ LEOPARDI. Diálogo da moda e a morte, p. 324-327.

${ }^{23}$ BENJAMIN. Passagens, p. 102-103.

${ }^{24}$ BENJAMIN. Passagens, p. 101-102.

${ }^{25}$ BENJAMIN. Passagens, p. 108.

${ }^{26}$ BENJAMIN. Origem do drama barroco alemão, p. 247. 